\title{
Arginase inhibition by piceatannol-3'-O- $\beta$-D-glucopyranoside improves endothelial dysfunction via activation of endothelial nitric oxide synthase in ApoE-null mice fed a high-cholesterol diet
}

\author{
AINIENG WOO $^{1 *}$, WOOSUNG SHIN ${ }^{1 *}$, TO DAO CUONG ${ }^{3}$, BYUNGSUN MIN $^{3}$, JEONG HYUNG LEE $^{2}$, \\ BYUNG HWA JEON $^{4}$ and SUNGWOO RYOO ${ }^{1}$ \\ Departments of ${ }^{1}$ Biology, ${ }^{2}$ Biochemistry, College of Natural Sciences, Kangwon National University, \\ Chuncheon 200-701; ${ }^{3}$ College of Pharmacy, Catholic University, Daegu 712-702; ${ }^{4}$ Department of Physiology, \\ School of Medicine, Chungnam National University, Daejeon 301-131, Republic of Korea
}

Received October 31, 2012; Accepted December 28, 2012

DOI: 10.3892/ijmm.2013.1261

\begin{abstract}
Elevated plasma cholesterol is a hallmark of numerous cardiovascular diseases that are closely linked to endothelial dysfunction indicating decreased nitric oxide $(\mathrm{NO})$ production in the endothelium. It has been previously demonstrated that piceatannol-3'-O- $\beta$-D-glucopyranoside (PG) inhibits arginase activity and reciprocally regulates NO production. Here, we aimed to ascertain whether PG ameliorates vascular function in wild-type (WT) and atherogenic model mice [apolipoprotein E-null mice $\left(\mathrm{ApoE}^{-/}\right)$] and to investigate the possible underlying mechanism. Preincubation of aortic vessels from WT mice fed a normal diet (ND) with PG attenuated vasoconstriction response to U46619 and phenylephrine (PE), while the vasorelaxant response to acetylcholine (Ach) was markedly enhanced in an endothelium-dependent manner. However, the endothelium-independent NO donor, sodium nitroprusside (SNP), did not change vessel reactivity. In thoracic aorta from ApoE ${ }^{-/-}$mice, a high-cholesterol diet (HCD) induced an increase in arginase activity, a decrease in NO release and an increase in reactive oxygen species generation that was reversed by treatment with PG. The effect of PG was associated with enhanced stability of the eNOS dimer and was not dependent on the expression levels of arginase II and eNOS proteins, although eNOS expression was increased in $\mathrm{ApoE}^{-/-}$mice fed an HCD. Furthermore, $\mathrm{PG}$ treatment attenuated the PE-dependent contractile response, and significantly improved the Ach-dependent vasorelaxation response in aortic rings from $\mathrm{ApoE}^{--}$mice fed an $\mathrm{HCD}$. On the other hand, $\mathrm{PG}$
\end{abstract}

Correspondence to: Professor Sungwoo Ryoo, Department of Biology, Kangwon National University, Kangwondae-gil 1, Chuncheon, Kangwon-do 200-701, Republic of Korea

E-mail: ryoosw08@kangwon.ac.kr

${ }^{*}$ Contributed equally

Key words: arginase, piceatannol-3'-O- $\beta$-D-glucopyranoside, endothelial dysfunction, endothelial nitric oxide synthase, apolipoprotein E-null mice incubation neither altered the contractile response to a high $\mathrm{K}^{+}$ solution nor the relaxation response to SNP. When analyzing the L-arginine content using high-performance liquid chromatography, PG incubation increased the intracellular L-arginine concentration. PG administration in the drinking water significantly reduced fatty streak formation in $\mathrm{ApoE}^{-1-}$ mice fed an HCD. These data indicate that PG improves the pathophysiology of cholesterol-mediated endothelial dysfunction. Therefore, we conclude that the development of PG as a novel effective therapy for preventing atherosclerotic diseases is warranted.

\section{Introduction}

Elevated plasma cholesterol, such as native low-density lipoprotein (LDL) and oxidized LDL (oxLDL), is a hallmark of numerous cardiovascular diseases including hypercholesterolemia, atherosclerosis, hypertension, heart failure, and diabetes. These diseases are closely linked with endothelial dysfunction indicating decreased nitric oxide $(\mathrm{NO})$ production in the endothelium. In the vasculature, $\mathrm{NO}$ is a vasoprotective molecule and plays a central role in vascular homeostasis by regulating vasoreactivity, platelet activation, leukocyte adhesion and smooth muscle cell migration and proliferation (1). It is well established that endothelial arginase constrains the activity of endothelial nitric oxide synthase (eNOS) by substrate depletion, thereby reducing NO bioavailability and contributing to vascular diseases. oxLDL, the primary pathogenic lipid in atherogenesis, activates human endothelial cell arginase II by stimulating the dissociation of arginase II from microtubules and also by inducing arginase II mRNA transcription (2). Furthermore, atherogenic-prone apolipoprotein E-null $\left(\mathrm{ApoE}^{-/}\right)$mice treated with an arginase inhibitor exhibit restored NO bioavailability and endothelial function, reactive oxygen species (ROS) production, and an arterial compliance similar to that observed in wild-type (WT) mice (3). Therefore, endothelial arginase may be a novel target for therapeutic drug design for vascular diseases such as atherosclerosis (3).

Rhubarb is the rhizome of Rheum undulatum and is commonly distributed in Asia. Many components of the 
rhizome possess diverse biological activities and have been reported as being able to counter allergic (4) and diabetic states (5), as having anti-oxidant properties (4), and as functioning as a vasorelaxant (6). Piceatannol, one of the active components of rhubarb, was recently found to inhibit lipooxygenase activity (7) and VSMC proliferation and migration (8). Recently, we reported that piceatannol-3'-O- $\beta$-D-glucopyranoside $(\mathrm{PG})$ is a potent inhibitor of arginase isoforms. PG inhibited the arginase isoforms in a dose-dependent manner, resulting in augmented NO production by enhancing eNOS dimer stabilization (9).

Based on these data, we hypothesized that $\mathrm{PG}$ regulates vascular function. Therefore, we examined whether PG improves NO/ROS production and endothelial dysfunction in ApoE ${ }^{-/}$mice fed a high-cholesterol diet (HCD). We also investigated whether arginase inhibition by $\mathrm{PG}$ restores L-arginine bioavailability and attenuates fatty streak formation in this atherogenic mouse model.

\section{Materials and methods}

Animals. Twenty 10-week-old male wild-type (WT) (C57BL/6J) and ApoE ${ }^{-/-}$mice (Dae Han Biolink Co.) were studied. The study was approved in accordance with the Guide for the Care and Use of Laboratory Animals (Institutional Review Board, Kangwon National University).

Protocol. To determine the effect of PG on vascular reactivity, we studied aortic rings isolated from 20 male C57BL/6J WT mice fed a normal diet (ND) and 20 male $\mathrm{ApoE}^{-/-}$mice fed an HCD (D12108C; Research Diet Inc., USA) for 6 weeks. Aortic rings were incubated with or without PG $(50 \mu \mathrm{mol} / \mathrm{l})$ for $18 \mathrm{~h}$ as previously described (9). For the pathological assay, $\mathrm{PG}$ was administered in the drinking water to $\mathrm{ApoE}^{-/-}$mice for 6 weeks when the mice were started on the HCD. Given that each mouse consumed $\sim 10 \mathrm{ml}$ water/day this represented a daily dose of $\sim 500 \mu \mathrm{g} / \mathrm{mouse} /$ day of PG.

Western blot analysis. Aortic vessel lysates were subjected to SDS-PAGE, and densitometry of the bands was conducted using NIH ImageJ (9). To analyze the ratio of eNOS dimer to monomer, proteins were separated using low-temperature SDS-PAGE followed by western blot analysis (9).

Aortic vascular tension assay. Male C57BL/6J mice fed an HCD were anesthetized using isoflurane, and the thoracic aorta was rapidly removed. The aortas were placed in icecold oxygenated Krebs-Ringer bicarbonate solution (in $\mathrm{mM}$ : $\mathrm{NaCl} 118.3, \mathrm{KCl} 4.7, \mathrm{MgSO}_{4} 1.2, \mathrm{KH}_{2} \mathrm{PO}_{4} 1.2, \mathrm{CaCl}_{2} 1.6$, $\mathrm{NaHCO}_{3} 25$, glucose 11.1), and cleared of adherent connective tissues. The mouse aortas were cut into $1.5-\mathrm{mm}$ rings and suspended between two wire stirrups $(150 \mu \mathrm{m})$ in a myograph (Multi Myograph System DMT-620) in $10 \mathrm{ml} \mathrm{Krebs-Ringer}$ solution $\left(95 \% \mathrm{O}_{2}-5 \% \mathrm{CO}_{2}, \mathrm{pH} 7.4,37^{\circ} \mathrm{C}\right)$. One stirrup was connected to a three-dimensional micromanipulator, and the other was connected to a force transducer. The rings were passively stretched at 10 -min intervals in increments of $100 \mathrm{mg}$ to reach optimal tone $(600 \mathrm{mg})$. After the arterial rings had been stretched to their optimal resting tone, the contractile response to $100 \mathrm{mM} \mathrm{KCl}$ was determined. The response to a maximal dose of $\mathrm{KCl}$ was used to normalize the responses to agonist across vessel rings. The dose response to the vasoconstrictors, PE $\left(10^{-9}-10^{-4} \mathrm{M}\right)$ and U46619 $\left(10^{-9}-10^{-5} \mathrm{M}\right)$, was performed first. This was followed by the dose response to the vasodilators, acetylcholine (Ach, $10^{-9}-10^{-5} \mathrm{M}$ ) and SNP $\left(10^{-9}-10^{-5} \mathrm{M}\right)$ after pre-constriction with $\mathrm{PE}\left(10^{-6} \mathrm{M}\right)$. At the end of the experiments, the NO-dependency of vasorelaxation was confirmed by adding the inhibitor of guanylate cyclase [1H-[1,2,4] oxadizolo[4,3-a]quinoxalin-1-one (ODQ), 10 $\left.\left.{ }^{-6} \mathrm{M}\right)\right]$.

Arginase activity. Tissue lysates were prepared using lysis buffer (50 mM Tris- $\mathrm{HCl}, \mathrm{pH} 7.5,0.1 \mathrm{mM}$ EDTA and protease inhibitors) by homogenization at $4^{\circ} \mathrm{C}$ followed by centrifugation for $20 \mathrm{~min}$ at $14,000 \mathrm{x} \mathrm{g}$ at $4^{\circ} \mathrm{C}$. The supernatants were used to assay for arginase activity as previously described (10).

Estimation of NO or ROS generation using DAF-FM or DHE in isolated mice aorta. Mice aortic rings were isolated and incubated overnight at $37^{\circ} \mathrm{C}$ in $5 \% \mathrm{CO}_{2}$ in Dulbecco's modified Eagle's medium containing $2 \%$ FBS and antibiotics (1X) in the presence of PG $(50 \mu \mathrm{mol} / \mathrm{l})(10)$. The fluorescence from the aortic endothelium was measured at different time intervals under microscopy (9).

Determination of intracellular L-arginine concentrations. The intracellular concentration of L-arginine was determined by high-performance liquid chromatography (HPLC) using pre-column derivatization with $o$-phthalaldehyde (OPA) by modification of a previously published method (11). L-arginine $(100 \mu \mathrm{mol} / \mathrm{l})$ was added to the cell lysate $(0.5 \mathrm{ml})$ as an internal standard. The samples were extracted on solid-phase extraction cartridges (CBA Bond Elute; Varian, Inc.). Recovery rates were $87.5 \pm 3.9 \%$. Eluates were dried over nitrogen and resuspended in double-distilled water for HPLC analysis. HPLC was performed on a computer-controlled Waters chromatography system (M600E) consisting of an automatic injector (M7725i; Waters Co.) and a fluorescence detector (FP-1520; Jasco Co.) located in the Central Laboratory of Kangwon National University. Samples were incubated for exactly $1 \mathrm{~min}$ with OPA reagent $(5.4 \mathrm{mg} / \mathrm{ml} \mathrm{OPA}$ in borate buffer, $\mathrm{pH} 8.4$, containing $0.4 \%$ 2-mercaptoethanol) before automatic injection for the HPLC. The OPA derivative of L-arginine was separated on a $150 \times 4.6 \mathrm{~mm}, 3.5-\mu \mathrm{m}$ Zorbax Eclipse XDB-C18 column with the fluorescence detector set at Ex $340 \mathrm{~nm}$ and Em $450 \mathrm{~nm}$. Samples were eluted from the column with $0.96 \%$ citric acid/ methanol (70:30), $\mathrm{pH} 6.8$, at a flow rate of $1.5 \mathrm{ml} / \mathrm{min}$.

Gross pathologic assessment of plaque. The extent of atherosclerosis in the aortas was quantified in an en face preparation. Digital color images of the aortas after staining with Oil Red O were analyzed using MetaMorph image analysis software (Molecular Devices, Sunnyvale, CA, USA).

Data analysis and statistics. Aortic vasoconstrictor responses are presented as percent change in the maximum response induced by $\mathrm{KCl}$. Vasodilator responses are expressed as a percentage of pre-constricted tension. The $\mathrm{EC}_{50}$ and the maximal response $\left(\mathrm{E}_{\max }\right)$ were calculated using nonlinear logistic regression analysis with Prism (GraphPad) software. All data are represented as means \pm standard error of at least four independent experiments. An unpaired Student's t-test or 
Table I. Vasoconstrictor responses in PG-treated and -untreated aortic rings.

\begin{tabular}{|c|c|c|c|c|c|}
\hline & \multicolumn{2}{|c|}{$\operatorname{LogEC}_{50}$} & \multicolumn{2}{|c|}{$\mathrm{E}_{\max }(\% \mathrm{KCl})$} & \multirow[b]{2}{*}{$\mathrm{n}$} \\
\hline & Untreated & PG & Untreated & PG & \\
\hline U46619 & $-6.59 \pm 0.06$ & $-6.42 \pm 0.11$ & $192.0 \pm 5.94$ & $155.2 \pm 8.61^{\mathrm{a}}$ & 6 \\
\hline $\mathrm{PE}$ & $-6.91 \pm 0.10$ & $-7.23 \pm 0.07^{\mathrm{a}}$ & $143.9 \pm 4.45$ & $116.9 \pm 2.31^{\mathrm{a}}$ & 7 \\
\hline
\end{tabular}

Values are means \pm standard error; $n$, number of mice. ${ }^{\text {a }} \mathrm{PG}$ vs. untreated, $\mathrm{P}<0.05$. PE, phenylephrine; $\mathrm{PG}$, piceatannol-3'-O- $\beta$-D-glucopyranoside
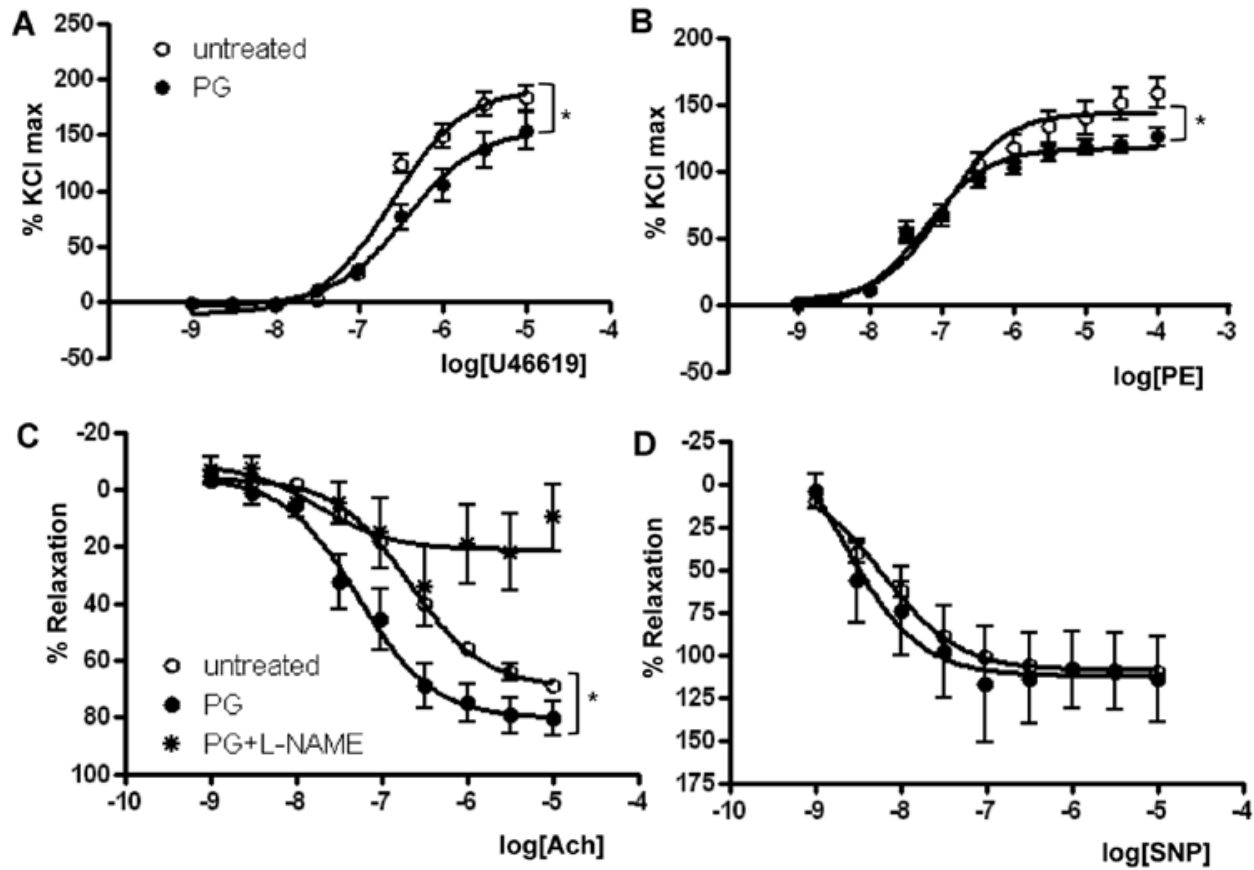

Figure 1. Effect of PG on vascular tension in WT mice fed an ND. The contractile response to the vasoconstrictors (A) U46619 and (B) PE was significantly attenuated in PG-treated $(50 \mu \mathrm{g} / \mathrm{ml})$ rings (untreated vs. PG-treated, $\left.{ }^{*} \mathrm{P}<0.01\right)$. Vessels were preconstricted to $\sim 60 \%$ of contractile $\mathrm{E}_{\max }$ with $\mathrm{PE}\left(10^{-6} \mathrm{M}\right)$ and cumulative dose responses to (C) Ach and (D) SNP were performed. The vasorelaxant $\mathrm{E}_{\max }$ and $\mathrm{EC}_{50}$ to Ach were enhanced in PG-treated aortic rings (untreated vs. PG-treated, "P<0.01), whereas L-NAME incubation completely prevented Ach-dependent vasorelaxation in PG-treated rings. In contrast, the efficacy of the vasorelaxant response to SNP was not significantly different.

2-way ANOVA was used to assess statistical significance. A value of $\mathrm{P}<0.05$ was accepted as significant.

\section{Results}

Vascular responses of $P G$-treated aortic rings from WT mice fed an ND. It was previously demonstrated that PG inhibits arginase activity and reciprocally increases NO production in the endothelium by enhancing eNOS dimerization. Therefore, we tested the vascular response to the vasoconstrictors, $\mathrm{PE}$ and U46619, and the vasorelaxants, Ach and SNP, with and without preincubation with PG.

As presented in Fig. 1 and Table I, the $\mathrm{E}_{\max }$ in response to U46619 in the PG-treated group $(155.2 \pm 8.6 \%)$ was significantly reduced when compared with that in the untreated group $(192.0 \pm 5.9 \%, \mathrm{P}<0.01)$ (Fig. 1A). Similar to the U46619 response, PG exposure significantly reduced the $\mathrm{E}_{\max }$ of PE-dependent vasoconstriction (Fig. 1B) (untreated vs. PG, 143.9 \pm 4.4 vs. $116.9 \pm 2.3 \%, \mathrm{P}<0.01, \mathrm{n}=7)$. The U46619 $\mathrm{EC}_{50}$ was significantly lower in the PG-treated group (untreated vs. PG, $-6.59 \pm 0.06$ vs. $-6.42 \pm 0.11 \mathrm{M}[\log (\mathrm{PE})], \mathrm{P}<0.05)$, and the $\mathrm{EC}_{50}$ in response to $\mathrm{PE}$ was more significantly reduced in the PG-treated group (untreated vs. PG, $-6.91 \pm 0.10$ vs. $-7.23 \pm 0.07 \mathrm{M}[\log (\mathrm{PE})]$, $\mathrm{P}<0.05)$. Therefore, we used PE to pre-constrict vessels in the experiments to test the vasorelaxant response.

To determine the effect of PG on endothelial-dependent vasorelaxation, mouse aortas were preincubated with or without PG and were preconstricted with PE $\left(10^{-6} \mathrm{M}\right)$. A dose-response curve to the endothelial-dependent vasodilator Ach was then constructed. Ach resulted in significant dosedependent relaxation in mouse aortas preincubated with PG. The $\mathrm{E}_{\max }$ values were $69.5 \pm 1.6$ vs. $80.3 \pm 4.0 \%$, and the $\mathrm{EC}_{50}$ was $-6.66 \pm 0.05$ vs. $-7.26 \pm 0.14 \mathrm{M}[\log$ (Ach)] for untreated and PG-incubated aortas, respectively $(\mathrm{n}=8, \mathrm{P}<0.05)$ (Fig. $1 \mathrm{C}$ and Table II). Interestingly, the enhanced relaxation response to Ach by PG incubation was completely prevented by treatment with L-NAME, a general NOS inhibitor.

The percentage of relaxation to SNP was similar between the untreated and PG-treated mice (Fig. 1D). $\mathrm{E}_{\max }$ values for untreated and PG-treated groups were 109.0 \pm 1.6 and 
Table II. Vasodilator responses in PG-treated and untreated aortic rings.

\begin{tabular}{|c|c|c|c|c|c|}
\hline & \multicolumn{2}{|c|}{$\operatorname{LogEC}_{50}$} & \multicolumn{2}{|c|}{$\mathrm{E}_{\max }(\% \mathrm{KCl})$} & \multirow[b]{2}{*}{$\mathrm{n}$} \\
\hline & Untreated & PG & Untreated & PG & \\
\hline Ach & $-6.66 \pm 0.05$ & $-7.26 \pm 0.14^{\mathrm{a}}$ & $69.5 \pm 1.61$ & $80.3 \pm 4.02^{\mathrm{a}}$ & 8 \\
\hline SNP & $-8.19 \pm 0.07$ & $-8.64 \pm 0.57$ & $109.0 \pm 1.62$ & $112.5 \pm 10.7$ & 5 \\
\hline
\end{tabular}

Values are means \pm standard error; $n$, number of mice. ${ }^{\text {PPG }}$ vs. untreated, $\mathrm{P}<0.05$. PE, phenylephrine; $\mathrm{PG}$, piceatannol-3'-O- $\beta$-D-glucopyranoside; SNP, sodium nitroprusside.
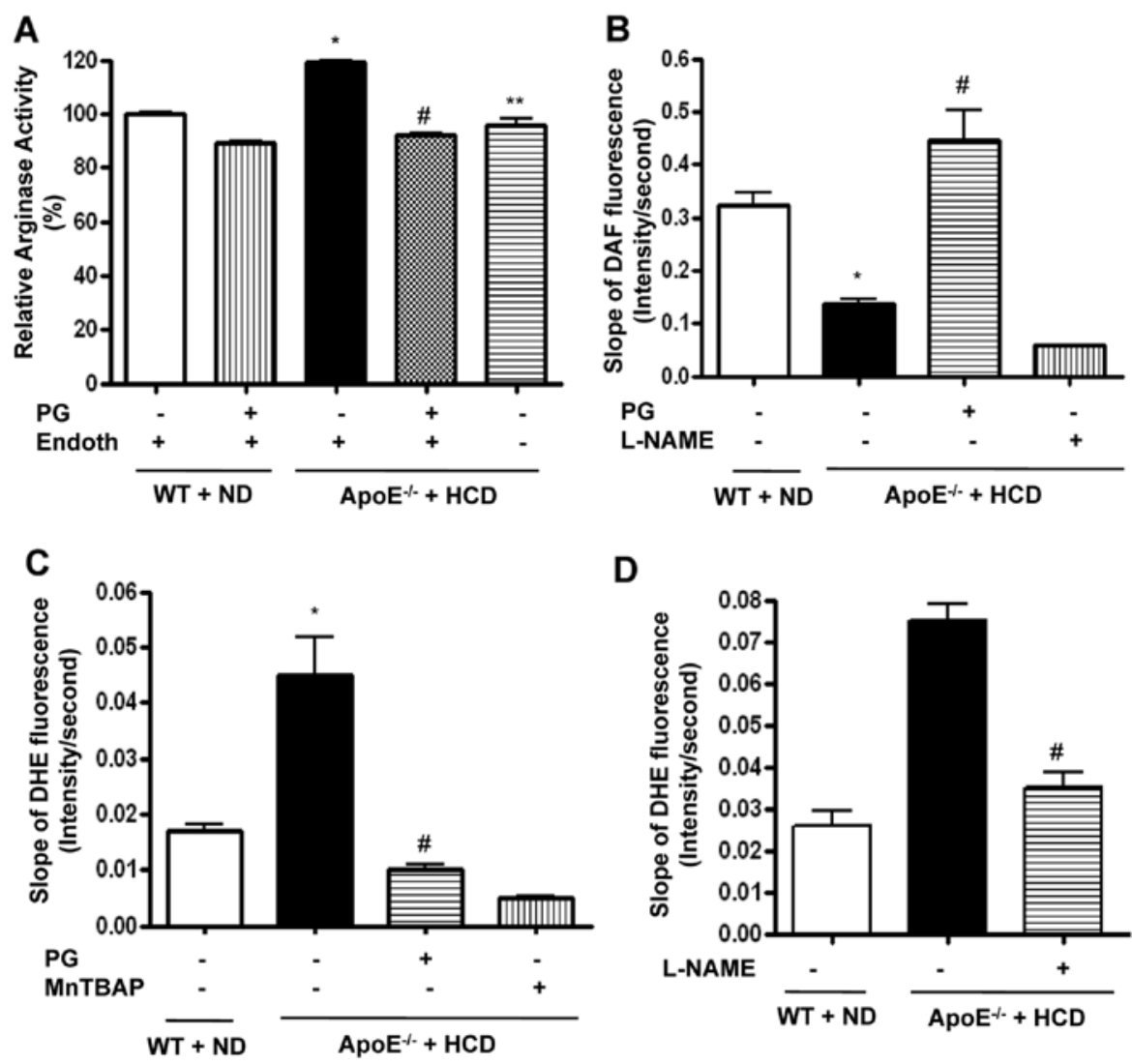

Figure 2. PG-dependent arginase inhibition improves endothelial NO production in $\mathrm{ApoE}^{-/}$mice fed an $\mathrm{HCD}$. Arginase activity was significantly increased in the endothelium of vessels from ApoE ${ }^{-/-}$mice fed an $\mathrm{HCD}$ for six weeks. This was blocked following incubation with $\mathrm{PG}\left(50 \mu \mathrm{g} / \mathrm{ml},{ }^{*} \mathrm{P}<0.01,{ }^{*} \mathrm{P}<0.01,{ }^{* *} \mathrm{P}<0.01\right.$, $\mathrm{n}=4$ ). (B) Vascular $\mathrm{NO}$ was measured in mouse aortas (en face, endothelial side up) by monitoring the change in the slope of DAF fluorescence ("P<0.01, $\left.{ }^{\#} \mathrm{P}<0.01\right)$. L-NAME $(10 \mu \mathrm{mol} / \mathrm{l})$ was used as a control, $\mathrm{n}=6$. (C) ROS production was measured in mouse aortas using O2*-specific fluorescent dye (DHE), and the slope of DHE fluorescence over time was determined ( $\left.\mathrm{P}<0.01,{ }^{*} \mathrm{P}<0.01\right)$. MnTBAP $(1 \mu \mathrm{mol} / \mathrm{l})$ was used as a negative control, $\mathrm{n}=6$. (D) Isolated vessels were treated with L-NAME $(10 \mu \mathrm{mol} / \mathrm{l})$, and DHE signals were measured $\left({ }^{\sharp} \mathrm{P}<0.01\right)$.

$112.5 \pm 10.7 \%$, respectively. $\mathrm{EC}_{50}$ values for untreated and PG-treated groups were $-8.19 \pm 0.07$ and $-8.64 \pm 0.57 \mathrm{M}$ $[\log (\mathrm{SNP})]$, respectively. Preincubation with PG and the presence of L-NAME as an eNOS inhibitor did not alter vascular responses to SNP in any groups (data not shown).

$P G$ inhibits arginase activity in mice fed an HCD and is associated with increased $N O$ generation and decreased ROS production. We analyzed the lipid profiles from sera $(\mathrm{n}=10)$ isolated from WT mice fed an ND and $\mathrm{ApoE}^{-/-}$mice fed an HCD. The total cholesterol $(100 \pm 2.3$ vs. $989.2 \pm 12.9 \mathrm{mg} / \mathrm{dl}$, $\mathrm{P}<0.01)$, LDL content $(3.0 \pm 1.2$ vs. $572.7 \pm 0.9 \mathrm{mg} / \mathrm{dl}, \mathrm{P}<0.01)$, and the triglyceride level $(31.0 \pm 1.9$ vs. $86.0 \pm 3.8 \mathrm{mg} / \mathrm{dl}, \mathrm{P}<0.01)$ of the $\mathrm{ApoE}^{-/}$mice fed an $\mathrm{HCD}$ were all significantly higher than levels of the WT mice fed an ND. HDL concentration was also significantly higher in $\mathrm{ApoE}^{-/}$mice fed an $\mathrm{HCD}(91.9 \pm 2.8$ vs. $688.6 \pm 9.6 \mathrm{mg} / \mathrm{dl}, \mathrm{P}<0.01$ ).

We wished to determine the effect of PG on arginase activity in aortic vessels of $\mathrm{ApoE}^{-/-}$mice fed an HCD. The HCD induced an increase in arginase activity, which was dominantly presented in the endothelium $\left(\mathrm{ApoE}^{-/}+\mathrm{HCD}\right.$ vs. $\mathrm{WT}+\mathrm{ND}, 119 \pm 1$ vs. $100 \pm 1 \%, \mathrm{P}<0.01 ; \mathrm{ApoE}^{-/-}+\mathrm{HCD}$ vs. $\mathrm{ApoE}^{-/-}+\mathrm{HCD}+$ Endoth, $96 \pm 4$ vs. $\left.119 \pm 1 \%, \mathrm{P}<0.01\right)$ (Fig. 2A). Preincubation of aortic rings with PG significantly decreased arginase activity in $\mathrm{ApoE}^{-/}$mice fed an $\mathrm{HCD}$ $\left(\mathrm{ApoE}^{-/}+\mathrm{HCD}+\right.$ Endoth $+\mathrm{PG}$ vs. ApoE ${ }^{-/}+\mathrm{HCD}+$ Endoth, 
A
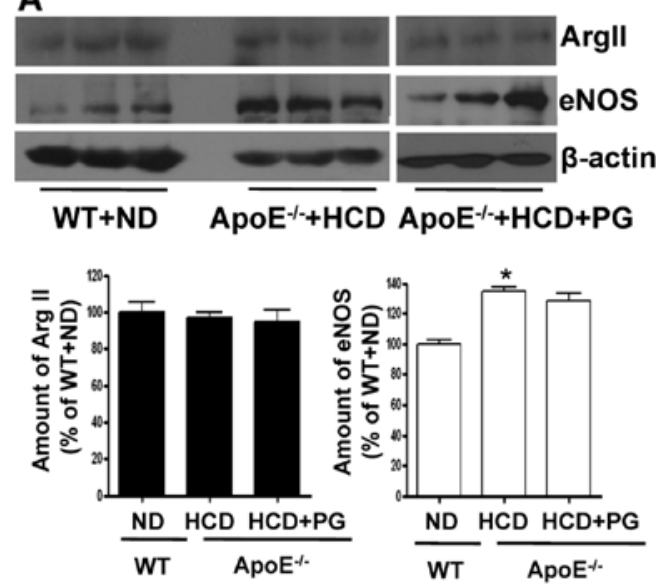

B
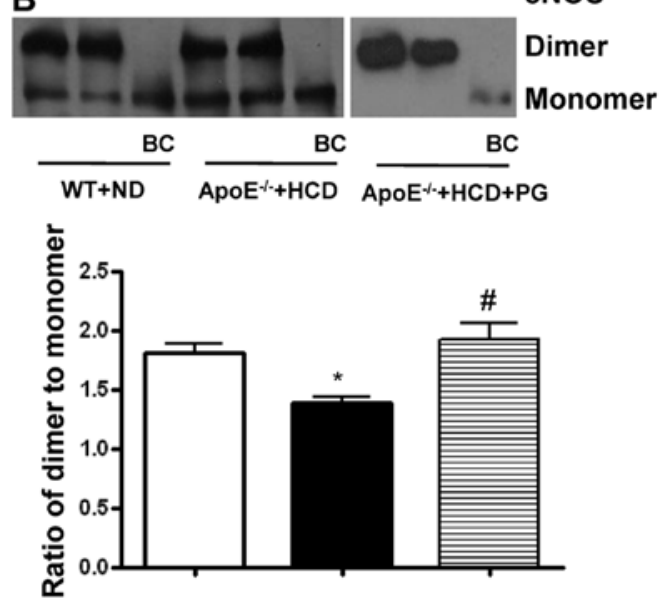

Figure 3. PG-dependent arginase inhibition restores HCD-dependent eNOS uncoupling. (A) Protein levels of arginase II and eNOS were analyzed after incubation of thoracic aortas from WT mice fed an ND and ApoE ${ }^{-/-}$mice fed an HCD with or without PG (50 $\left.\mu \mathrm{g} / \mathrm{ml}\right)$. Incubation with PG had no effect on arginase II expression. Expression of eNOS, however, was significantly increased in $\mathrm{ApoE}^{-/}$mice fed an $\mathrm{HCD}\left({ }^{*} \mathrm{P}<0.01\right)$. (B) eNOS uncoupling induced by an $\mathrm{HCD}$ was markedly restored by incubating isolated aortas with PG.

$92 \pm 2$ vs. $119 \pm 1 \%, \mathrm{P}<0.01)$ and in WT fed an ND. We next tested whether PG-dependent arginase inhibition resulted in increased NO production using an NO-sensitive fluorescence dye, DAF-FM [3-amino-4-(N-methylamino)-2',7'-difluorofluorescein] diacetate, over the indicated time intervals. HCD induced a decrease in the slope of DAF fluorescence (Fig. 2B) $\left(\mathrm{ApoE}^{-/-}+\mathrm{HCD}\right.$ vs. WT $+\mathrm{ND}, 0.13 \pm 0.02$ vs. $0.32 \pm 0.05$ change in DAF fluorescence/sec, $\mathrm{P}<0.01)$. This was improved by incubation with $\mathrm{PG}\left(\mathrm{ApoE}^{-/-}+\mathrm{HCD}+\mathrm{PG}\right.$ vs. $\mathrm{ApoE}^{-/-}+\mathrm{HCD}, 0.44 \pm 0.11$ vs. $0.13 \pm 0.02$ change in DAF fluorescence/sec, $\mathrm{P}<0.01)$. On the other hand, incubation with $\mathrm{N}^{\mathrm{G}}$-nitro-L-arginine methyl ester (L-NAME) acutely decreased the slope of DAF fluorescence (0.06 \pm 0.01 change in DAF fluorescence/sec).

To determine whether increased NO production by arginase inhibition contributes to ROS reduction, we measured $\mathrm{O} 2^{\circ}$ generation using the $\mathrm{O} 2{ }^{*}$-sensitive dye, dihydroethidium (DHE), in the endothelia of WT and $\mathrm{ApoE}^{-/-}$mice. The time-dependent intensity of DHE fluorescence was increased in $\mathrm{ApoE}^{-/-}$mice fed an HCD compared to WT mice fed an ND (Fig. 2C) $\left(\mathrm{ApoE}^{-/-}+\mathrm{HCD}\right.$ vs. WT $+\mathrm{ND}, 0.045 \pm 0.015$ vs. $0.017 \pm 0.003$ change in $\mathrm{DHE}$ fluorescence/sec, $\mathrm{P}<0.01)$. Preincubation with $\mathrm{PG}$ reduced the slope of DHE fluorescence in $\mathrm{ApoE}^{-/-}$fed an $\mathrm{HCD}\left(\mathrm{ApoE}^{-/-}+\mathrm{HCD}+\mathrm{PG}\right.$ vs. ApoE $\mathrm{E}^{-/-}+\mathrm{HCD}, 0.01 \pm 0.002$ vs. 0.045 \pm 0.015 change in $\mathrm{DHE}$ fluorescence/sec, $\mathrm{P}<0.01)$. MnTBAP, a ROS scavenger, completely quenched DHE signal. We next measured ROS production in the presence of NOS inhibitor, L-NAME. Interestingly, L-NAME prevented ROS production in $\mathrm{ApoE}^{-/-}$mice fed an $\mathrm{HCD}$ (Fig. 2D) (ApoE ${ }^{-/}+\mathrm{HCD}$ + L-NAME vs. ApoE ${ }^{-/-}+\mathrm{HCD}, 0.035 \pm 0.01$ vs. $0.075 \pm 0.01$ change in DHE fluorescence/sec, $\mathrm{P}<0.01)$.

$P G$ enhances the stability of the eNOS dimer in ApoE ${ }^{-/-}$mice fed an HCD without affecting protein expression levels. To understand the underlying mechanism of how PG increases $\mathrm{NO}$ production and reduces ROS generation in aorta from $\mathrm{ApoE}^{-/}$mice fed an HCD, we performed a western blot analysis of arginase II and eNOS in the endothelium. The expression level of arginase II was not significantly different between untreated- and PG-treated aortas isolated from ApoE ${ }^{-/}$ mice fed an HCD (ApoE ${ }^{-/-}+\mathrm{HCD}$ vs. ApoE ${ }^{-/-}+\mathrm{HCD}+\mathrm{PG}$, $96.9 \pm 5.1$ vs. $94.8 \pm 10.0 \%$, ns) compared to that of WT fed

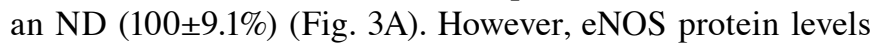
were significantly increased in $\mathrm{ApoE}^{-/}$mice fed an HCD $\left(\mathrm{ApoE}^{-/}+\mathrm{HCD}\right.$ vs. WT + ND, $134.2 \pm 5.9$ vs. $100 \pm 4.7 \%$, $\mathrm{P}<0.01)$. $\mathrm{PG}$ incubation had no effect on the protein levels of eNOS (ApoE $E^{-/}+\mathrm{HCD}$ vs. ApoE ${ }^{-/}+\mathrm{HCD}+\mathrm{PG}, 134.2 \pm 5.9$ vs. $128.5 \pm 8.3 \%, \mathrm{~ns})$. On the other hand, the ratio of eNOS dimer/ monomer was significantly decreased in the aortas of $\mathrm{ApoE}^{-/}$ mice fed an HCD from $1.83 \pm 0.27$ to $1.18 \pm 0.08(\mathrm{P}<0.01)$. When incubated with $\mathrm{PG}$, this value in $\mathrm{ApoE}^{-/-}$mouse aortas was restored to $1.92 \pm 0.25$ (Fig. $3 \mathrm{~B})(\mathrm{P}<0.01)$.

Effect of PG on aortic vascular reactivity in ApoE ${ }^{-/-}$mice fed an HCD. PG-dependent arginase inhibition enhanced vascular function in WT mice fed an ND (Fig. 1 and Table I). This also reciprocally increased NO production and decreased ROS generation by enhancing the stability of the eNOS dimer in $\mathrm{ApoE}^{-/-}$mice fed an HCD. Therefore, we tested whether PG restores impaired vascular function in $\mathrm{ApoE}^{-/-}$mice fed an $\mathrm{HCD}$.

The vasoconstriction response induced by a $60 \mathrm{mM} \mathrm{K}$ solution was significantly higher in thoracic aortas isolated from $\mathrm{ApoE}^{-/-}$mice fed an HCD compared to those isolated from WT mice fed an ND (Fig. 4A) $\left(\mathrm{ApoE}^{-/-}+\mathrm{HCD}\right.$ vs. $\mathrm{WT}+\mathrm{ND}, 150.2 \pm 9.6$ vs. $100 \pm 11.4 \%, \mathrm{P}<0.01)$. $\mathrm{PG}$ incubation had no effect on $\mathrm{K}^{+}$-induced vasoconstriction $\left(\mathrm{ApoE}^{-/}+\mathrm{HCD}\right.$ vs. $\mathrm{ApoE}^{-/-}+\mathrm{HCD}+\mathrm{PG}, 150.2 \pm 9.6$ vs. $147.3 \pm 13.4 \%$, ns). The vasoconstriction response to $\mathrm{PE}$ was markedly reduced in $\mathrm{ApoE}^{-/-}$mice fed an HCD in a dose-response manner. As presented in Fig. 4B, the $\mathrm{E}_{\max }$ value in aortas from $\mathrm{ApoE}^{-/-}$mice fed an HCD compared with WT mice fed an ND was significantly decreased (WT + ND vs. $\mathrm{ApoE}^{-/-}+\mathrm{HCD}, 150.5 \pm 4.16$ vs. $119.9 \pm 3.15 \%, \mathrm{P}<0.01)$. $\operatorname{LogEC}_{50}$ values were also significantly decreased $\left(\mathrm{WT}+\mathrm{ND}\right.$ vs. ApoE ${ }^{-/-}+\mathrm{HCD},-8.2 \pm 0.07$ vs. $-7.9 \pm 0.06 \mathrm{M}[\log (\mathrm{PE})], \mathrm{P}<0.01)$. Interestingly, preincubation of vessels from $\mathrm{ApoE}^{-/-}$mice fed an $\mathrm{HCD}$ with $\mathrm{PG}$ resulted in a marked decrease in the maximal vasoconstrictor response to $\mathrm{PE}\left(\mathrm{ApoE}^{-/-}+\mathrm{HCD}\right.$ vs. ApoE $\mathrm{E}^{-/-}+\mathrm{HCD}+\mathrm{PG}, 119.9 \pm 3.15$ vs. $79.6 \pm 5.2 \%, \mathrm{P}<0.01)$. 

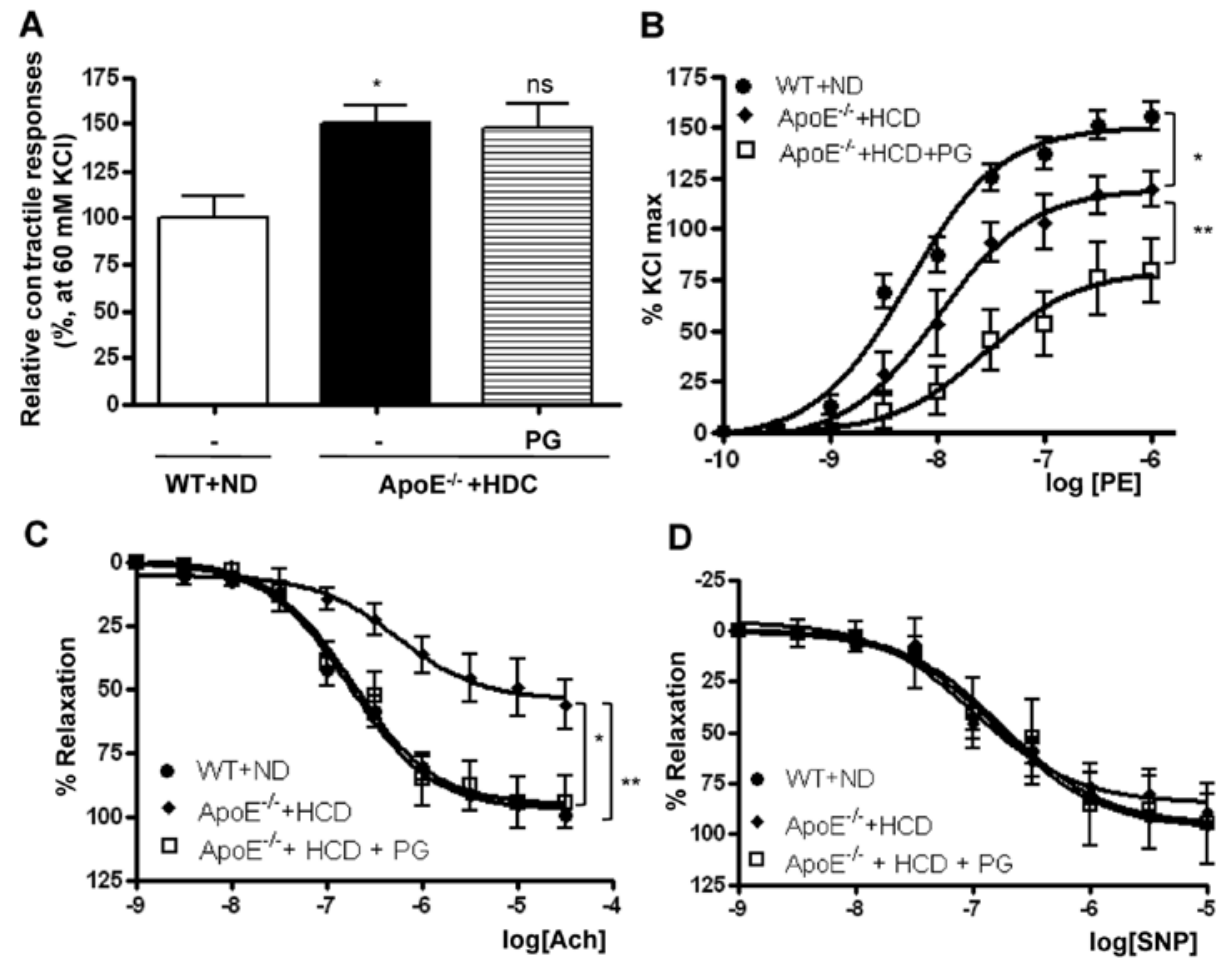

Figure 4. Preincuabtion with PG improves endothelial dysfunction in aortas from $A p o E^{-/}$mice fed an $\mathrm{HCD}$. (A) Maximal tension to a $\mathrm{K}^{+}$solution (60 $\mathrm{mM}$ $\mathrm{KCl})$ in $\mathrm{ApoE}^{-/}$mice + $\mathrm{HCD}$ was significantly higher compared with that in WT mice fed an ND ( $\left.\mathrm{P}<0.01, \mathrm{n}=8\right)$. (B) The maximal vascular tension $\left(\mathrm{E}_{\mathrm{max}}\right)$ and the $\mathrm{EC}_{50}$ response to $\mathrm{PE}\left(10^{-9}-10^{-4} \mathrm{~mol} / \mathrm{l}\right)$ were significantly reduced in aortas of $\mathrm{ApoE}^{-/}$mice fed an $\mathrm{HCD}$ compared with WT mice fed an ND, which was attenuated by preincubation with $\mathrm{PG}\left(50 \mu \mathrm{g} / \mathrm{ml},{ }^{*} \mathrm{P}<0.01,{ }^{* *} \mathrm{P}<0.01, \mathrm{n}=8\right)$. (C) Vessels were preconstricted to $50-75 \%$ of the contractile $\mathrm{E}_{\max }$ with $\mathrm{PE}\left(10^{-6} \mathrm{~mol} / \mathrm{l}\right)$, and a cumulative dose-response to Ach was performed. The vasorelaxant $\mathrm{E}_{\max }$ to Ach was markedly attenuated in rings isolated from ApoE $\mathrm{E}^{-/}$mice fed an HCD compared with WT mice fed an ND, whereas PG preincubation with aortas from $\mathrm{ApoE}^{-1-}$ mice fed an $\mathrm{HCD}$ enhanced the vasorelaxant response $\left({ }^{*} \mathrm{P}<0.01\right.$, ${ }^{* *} \mathrm{P}<0.01, \mathrm{n}=8$ ). (D) In contrast, the efficacy of vasorelaxant responses to SNP was not changed in all rings.

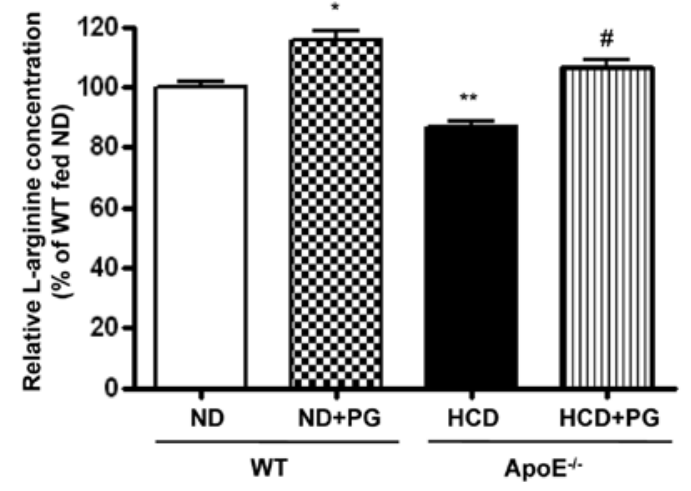

Figure 5. Effect of arginase inhibition by PG on intracellular L-arginine content. Aortic vessels were incubated with or without PG, and intracellular $\mathrm{L}$-arginine concentrations were measured using HPLC. The L-arginine levels were increased in PG-treated aortas of WT mice fed an ND $\left({ }^{*} \mathrm{P}<0.01\right)$, and reduced L-arginine content in aortas of $\mathrm{ApoE}^{-/-}$mice fed an $\mathrm{HCD}$ was restored by arginase inhibition with $\mathrm{PG}\left({ }^{* *} \mathrm{P}<0.01,{ }^{*} \mathrm{P}<0.01, \mathrm{n}=4\right)$.

To determine the effect of PG on the endothelium-dependent vasorelaxation in $\mathrm{ApoE}^{-/-}$mice fed an $\mathrm{HCD}$, mouse aortas were preconstricted with PE $\left(10^{-6} \mathrm{M}\right)$, and dose-response curves were constructed to the endothelium-dependent vasorelaxant, Ach, and the endothelium-independent $\mathrm{NO}$ donor, SNP. Ach resulted in significant dose-dependent relaxation in mouse aortas. The vasorelaxant responses in aortic rings from $\mathrm{ApoE}^{-/}$mice fed an HCD were significantly attenuated compared with those from WT mice fed an ND. The $\mathrm{E}_{\max }$ was $54.3 \pm 4.5$ vs. $97.1 \pm 2.1 \%$ (Fig. $4 \mathrm{C})\left(\mathrm{ApoE}^{-/-}+\mathrm{HCD}\right.$ vs. $\mathrm{WT}+\mathrm{ND}, \mathrm{P}<0.01)$. The reduced response of the aortic rings from HCD-fed mice was markedly improved by incubation with $\mathrm{PG}\left(\mathrm{ApoE}^{-/}+\mathrm{HCD}\right.$ vs. $\mathrm{ApoE} \mathrm{E}^{-/}+\mathrm{HCD}+\mathrm{PG}, 54.3 \pm 4.5$ vs. $95.3 \pm 4.5 \%, \mathrm{P}<0.01)$. However, the $\log \mathrm{EC}_{50}$ values were not significantly changed (WT + ND, -6.77 $\pm 0.06 ; \mathrm{ApoE}^{-/}+\mathrm{HCD}$, $\left.-6.94 \pm 0.12 ; \mathrm{ApoE}^{-/}+\mathrm{HCD}+\mathrm{PG},-6.74 \pm 0.13 \mathrm{M}[\log (\mathrm{Ach})]\right)$. SNP induced a maximal relaxant response in aortas from the HCD-fed mice that was similar to responses in the aortas from the ND-fed WT mice and from aortas from the HCD-fed mice following PG incubation (Fig. 4D).

$P G$ incubation restores intracellular L-arginine content. Given that upregulation of arginase activity regulates NOS activity by limiting L-arginine bioavailability, we measured the intracellular L-arginine concentration by OPA derivatization. Arginase inhibition by PG resulted in an increase in $\mathrm{L}$-arginine levels in $\mathrm{WT}$ aorta (WT + ND + PG vs. WT + ND, $115.5 \pm 6.5$ vs. $100 \pm 3.8 \%, \mathrm{P}<0.05$ ) (Fig. 5). On the other hand, L-arginine content was significantly decreased in the aortas of $\mathrm{ApoE}^{-/}$mice fed an $\mathrm{HCD}\left(\mathrm{ApoE}^{-/}+\mathrm{HCD}\right.$ vs. WT + ND, $86.7 \pm 4.0$ vs. $100 \pm 3.8 \%, \mathrm{P}<0.01)$. This decreased content was attenuated by incubation with PG $\left(\mathrm{ApoE}^{-/}+\mathrm{HCD}+\mathrm{PG}\right.$ vs. $\mathrm{ApoE}^{-/}+\mathrm{HCD}, 106.4 \pm 4.6$ vs. $\left.86.7 \pm 4.0 \%, \mathrm{P}<0.01\right)$.

$P G$ decreases fatty streak formation in $A p o E^{-/}$mice fed an $H C D$. PG reduced the area of the aorta with fatty streaks (Fig. 6A), as quantified by staining with the lipid dye Oil Red 

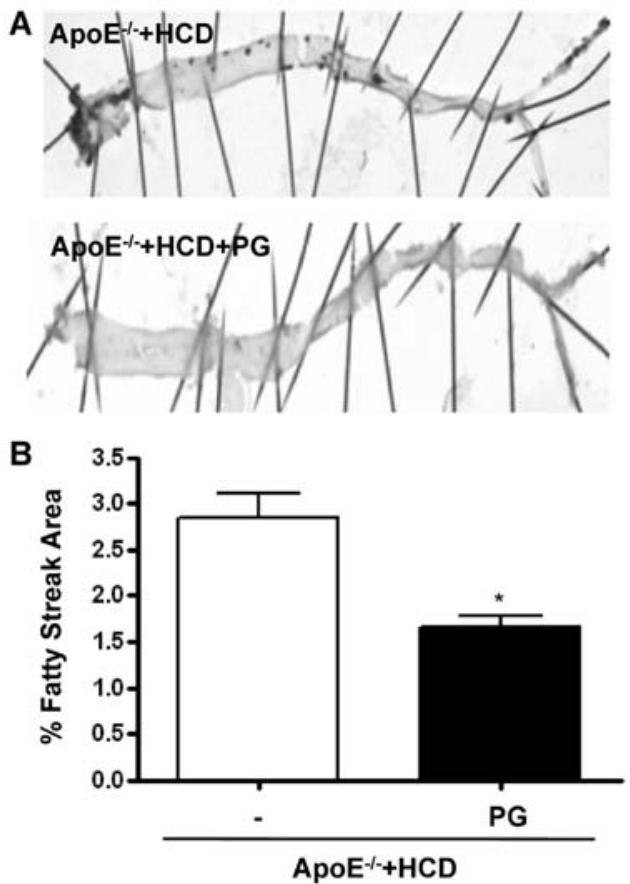

Figure 6. PG reduces fatty streak formation in $\mathrm{ApoE}^{-/}$mice. (A) A representative descending thoracic aorta stained with Oil Red $O$ shows the fatty streak area. (B) The cumulative quantitative assessment of fatty streak area was determined by pixel count of the red-stained area.

O (Fig. 6B) $\left(\mathrm{ApoE}^{-/-}+\mathrm{HCD}+\mathrm{PG}\right.$ vs. $\mathrm{ApoE}^{-/-}+\mathrm{HCD}, 2.8 \pm 0.4$ vs. $1.6 \pm 0.2 \%, \mathrm{P}<0.01)$.

\section{Discussion}

We previously established that PG is an active component of rhubarb that inhibits arginase I and II activity and reciprocally regulates $\mathrm{NO} / \mathrm{ROS}$ generation by enhancing the stability of the eNOS dimer. Here, we demonstrated that in aortic rings isolated from WT mice fed an ND, PG attenuated the response to vasoconstrictors U46619 and PE and enhanced the response to the vasorelaxant Ach in an endothelium-dependent manner. PG did not alter the response to the NO donor, SNP. Furthermore, in atherogenic model mice $\left(\mathrm{ApoE}^{-/}\right)$fed an $\mathrm{HCD}$, arginase activity was increased, NO production was decreased, ROS production was increased. All of these were significantly reversed by treatment with PG. Furthermore, PG treatment enhanced eNOS coupling by increasing L-arginine bioavailability and reduced fatty streak formation. PG treatment attenuated the impaired vascular responses to both, $\mathrm{PE}$ and Ach, in $\mathrm{ApoE}^{-/-}$mice fed an HCD.

Arginase negatively regulates eNOS-dependent NO production in endothelial cells. Thus, increased arginase activity has been shown to contribute to reduced NO bioavailability in several pathologies including vascular dysfunction $(10,12,13)$, asthma (14), erectile dysfunction (15), aging (12), and atherosclerosis $(3,16)$. oxLDL, a prime atherogenic agent, increases arginase activity by two distinct mechanisms: transcriptional upregulation and a posttranslational mechanism that dissociates the enzyme from the microtubule, resulting in activation (10). This oxLDL-dependent effect on arginase activity is one possible mechanism by which high cholesterol may lead to endothelial dysfunction dysregulating NO production.
NO has multiple vasoprotective characteristics (1). NO-based therapeutics are under investigation and include dietary L-arginine (17-19), drug-eluting stents (20), inhalational NO gas $(21,22)$, and NOS gene therapy $(23,24)$. Here we investigated the potential of PG, an inhibitor of arginase, as a novel NO-based therapeutic. PG improved HCD-induced endothelial dysfunction by attenuating the vasoconstriction response to PE and U46619, and it also augmented the vasorelaxation response to Ach by increasing NO bioavailability.

In aortic rings isolated from $\mathrm{ApoE}^{-/-}$mice fed an $\mathrm{HCD}$, vasoconstriction induced by a high $\mathrm{K}^{+}$solution was increased when compared to those isolated from WT mice fed an ND. This increase observed in $\mathrm{ApoE}^{-/-}$mouse tissues may be due to changes in the properties of the smooth muscle itself, rather than from injury to the endothelial cells. Alterations in smooth muscle cell function would be expected to occur when considering the morphological and biochemical changes observed in vascular tissues during cholesterol-induced atherogenesis; i.e., an increase in foam cells or in cell proliferation or a decrease in $\mathrm{Na}^{+} / \mathrm{K}^{+}$-ATPase activity (25).

The expression of inducible nitric oxide synthase (iNOS) has also been reported in atherosclerotic lesions (26). Therefore, increased iNOS expression and/or activity may be an additional possible mechanism to explain the decreased contraction in the aortic rings of these mice in response to PE. This enhanced iNOS activity does not require an increase in cytosolic $\mathrm{Ca}^{2+}$, and this may help explain how the observed decreased contraction was $\mathrm{Ca}^{2+}$-independent. Indeed, elevated cGMP content was found in atherosclerotic aortas from atherogenic rabbits (27). This observation indicates that an absence of NO or relative deficiency of NO resulted in compensatory upregulation of a downstream pathway.

Paradoxically, eNOS expression/abundance is actually increased in most animal models of atherosclerosis (28). This is consistent with observations in eNOS-deficient and eNOSoverexpressing mice in which an HCD resulted in decreased and increased measures of atherosclerosis, respectively $(29,30)$. Interestingly, $\mathrm{NO}$ production in $\mathrm{ApoE}^{-/-}$mice fed an $\mathrm{HCD}$ was decreased despite an increase in eNOS expression, suggesting that coupling rather than protein abundance is critical. Furthermore, eNOS inhibition with L-NAME in $\mathrm{ApoE}^{-/-}$mice fed an HCD significantly decreased ROS production, which suggests that uncoupled eNOS is an important ROS-producing enzyme in atherogenesis (Fig. 2D). Several mechanisms could explain eNOS uncoupling under pathophysiological conditions, including: i) substrate (L-arginine) depletion; ii) cofactor (BH4) depletion; iii) loss of dimerization; and iv) altered eNOS phosphorylation. These are interrelated and depend on the spatial confinement of NO signaling and the nitroso-redox milieu. NOS uncoupling in the setting of cofactor (BH4) or substrate (L-arginine) limitations could be amplified by an overabundance of the enzyme itself. This is consistent with our results (Figs. 2 and 3). Our data suggest that the upregulation of arginase results in NOS uncoupling, and arginase inhibition results in recoupling (Fig. 3B), with restoration of the nitrosoredox balance of endothelium function (Fig. 4).

In fact, we found that the L-arginine concentration was $66.6 \mu \mathrm{mol} / \mathrm{mg}$ protein in WT mice fed an ND and $57.7 \mu \mathrm{mol} / \mathrm{mg}$ protein in $\mathrm{ApoE}^{-/-}$mice fed an HCD. Previous studies (31-33) have demonstrated that endothelial cells contain two pools of 
L-arginine: i) pool I, regulated by the cationic transporter and can be depleted by cationic amino acid L-lysine, ii) pool II (pool IIA and IIB), accessible to eNOS but is not freely exchangeable with extracellular L-lysine (or L-arginine). Arg II specifically in mitochondria utilizes pool IIB. Pool IIB may be influenced by arginase and thus modulates the local concentration of L-arginine available to eNOS. Although our study did not distinguish the L-arginine pools, we demonstrated that arginase activity is involved in the regulation of the intracellular L-arginine concentration (Fig. 5). The relationship between arginase activity and L-arginine concentration was also shown in the plasma of mice (32).

Atherosclerosis is defined as a chronic inflammatory disease that is the result of activation and inhibition of multiple complex interacting mechanisms. Overall atherosclerotic process and fatty streak formation are inhibited by NO and enhanced by ROS. Despite advanced fatty streak development in the $\mathrm{ApoE}^{-/-}$mice, arginase inhibition with $\mathrm{PG}$, thereby increasing NO bioavailability and decreasing ROS production, significantly decreased fatty streak formation (Fig. 6).

In summary, we present the novel molecule PG that enhanced vascular function in WT mice, and improved impaired vascular function and reduced fatty streak formation in an atherosclerotic mouse $\left(\mathrm{ApoE}^{-/-}\right)$model fed an HCD. PG inhibited arginase activity and reciprocally increased NO production through enhanced stability of the eNOS dimer in aortic rings isolated from $\mathrm{ApoE}^{-/-}$mice fed an HCD. These insights suggest $\mathrm{PG}$ as the basis for development of safe and effective preventative therapies for atherosclerotic disease.

\section{Acknowledgements}

This study was supported by the Basic Science Research Program of the National Research Foundation of Korea (NRF), funded by the Ministry of Education, Science and Technology (2012-046921 and 2012-0006812).

\section{References}

1. Moncada S and Higgs A: The L-arginine-nitric oxide pathway. $\mathrm{N}$ Engl J Med 329: 2002-2012, 1993.

2. Ryoo S, Lemmon CA, Soucy KG, et al: Oxidized low-density lipoprotein-dependent endothelial arginase II activation contributes to impaired nitric oxide signaling. Circ Res 99: 951-960, 2006.

3. Ryoo S, Gupta G, Benjo A, et al: Endothelial arginase II: a novel target for the treatment of atherosclerosis. Circ Res 102: 923-932, 2008.

4. Matsuda H, Morikawa T, Toguchida I, Park JY, Harima S and Yoshikawa M: Antioxidant constituents from rhubarb: structural requirements of stilbenes for the activity and structures of two new anthraquinone glucosides. Bioorg Med Chem 9: 41-50, 2001.

5. Choi SZ, Lee SO, Jang KU, et al: Antidiabetic stilbene and anthraquinone derivatives from Rheum undulatum. Arch Pharm Res 28: 1027-1030, 2005.

6. Moon MK, Kang DG, Lee JK, Kim JS and Lee HS: Vasodilatory and anti-inflammatory effects of the aqueous extract of rhubarb via a NO-cGMP pathway. Life Sci 78: 1550-1557, 2006.

7. Ngoc TM, Minh PT, Hung TM, et al: Lipoxygenase inhibitory constituents from rhubarb. Arch Pharm Res 31: 598-605, 2008.

8. Choi KH, Kim JE, Song NR, et al: Phosphoinositide-3-kinase is a novel target of piceatannol for inhibiting PDGF-BB-induced proliferation and migration in human aortic smooth muscle cells. Cardiovasc Res 85: 836-844, 2010.

9. Woo A, Min B and Ryoo S: Piceatannol-3'-O-beta-Dglucopyranoside as an active component of rhubarb activates endothelial nitric oxide synthase through inhibition of arginase activity. Exp Mol Med 42: 524-532, 2010.
10. White AR, Ryoo S, Li D, et al: Knockdown of arginase I restores NO signaling in the vasculature of old rats. Hypertension 47: 245-251, 2006.

11. Boger RH, Bode-Boger SM, Mugge A, et al: Supplementation of hypercholesterolaemic rabbits with L-arginine reduces the vascular release of superoxide anions and restores NO production. Atherosclerosis 117: 273-284, 1995.

12. Berkowitz DE, White R, Li D, et al: Arginase reciprocally regulates nitric oxide synthase activity and contributes to endothelial dysfunction in aging blood vessels. Circulation 108: 2000-2006, 2003.

13. Santhanam L, Lim HK, Miriel V, et al: Inducible NO synthase dependent $\mathrm{S}$-nitrosylation and activation of arginase1 contribute to age-related endothelial dysfunction. Circ Res 101: 692-702, 2007.

14. Maarsingh H, Zaagsma J and Meurs H: Arginase: a key enzyme in the pathophysiology of allergic asthma opening novel therapeutic perspectives. Br J Pharmacol 158: 652-664, 2009.

15. Christianson DW: Arginase: structure, mechanism, and physiological role in male and female sexual arousal. Acc Chem Res 38: 191-201, 2005.

16. Yang $\mathrm{Z}$ and Ming XF: Endothelial arginase: a new target in atherosclerosis. Curr Hypertens Rep 8: 54-59, 2006.

17. Wilson AM, Harada R, Nair N, Balasubramanian N and Cooke JP: L-arginine supplementation in peripheral arterial disease: no benefit and possible harm. Circulation 116: 188-195, 2007.

18. Walker HA, McGing E, Fisher I, et al: Endothelium-dependent vasodilation is independent of the plasma L-arginine/ADMA ratio in men with stable angina: lack of effect of oral $\mathrm{L}$-arginine on endothelial function, oxidative stress and exercise performance. J Am Coll Cardiol 38: 499-505, 2001.

19. Blum A, Hathaway L, Mincemoyer R, et al: Oral L-arginine in patients with coronary artery disease on medical management. Circulation 101: 2160-2164, 2000.

20. Ansel GM and Lumsden AB: Evolving modalities for femoropopliteal interventions. J Endovasc Ther 16 (Suppl 2): II82-II97, 2009.

21. Ichinose F, Roberts JD Jr and Zapol WM: Inhaled nitric oxide: a selective pulmonary vasodilator: current uses and therapeutic potential. Circulation 109: 3106-3111, 2004.

22. Griffiths MJ and Evans TW: Inhaled nitric oxide therapy in adults. N Engl J Med 353: 2683-2695, 2005.

23. Barbato JE, Kibbe MR and Tzeng E: The emerging role of gene therapy in the treatment of cardiovascular diseases. Crit Rev Clin Lab Sci 40: 499-545, 2003.

24. Kibbe MR and Tzeng E: Nitric oxide synthase gene therapy in vascular pathology. Semin Perinatol 24: 51-54, 2000.

25. Ibengwe JK and Suzuki H: Changes in mechanical responses of vascular smooth muscles to acetylcholine, noradrenaline and high-potassium solution in hypercholesterolemic rabbits. $\mathrm{Br} \mathrm{J}$ Pharmacol 87: 395-402, 1986.

26. Arthur JF, Yin ZL, Young HM and Dusting GJ: Induction of nitric oxide synthase in the neointima induced by a periarterial collar in rabbits. Arterioscler Thromb Vasc Biol 17: 737-740, 1997.

27. Rupin A, Behr D and Verbeuren TJ: Increased activity of guanylate cyclase in the atherosclerotic rabbit aorta: role of non-endothelial nitric oxide synthases. Br J Pharmacol 119: 1233-1238, 1996.

28. Kawashima S: The two faces of endothelial nitric oxide synthase in the pathophysiology of atherosclerosis. Endothelium 11: 99-107, 2004.

29. Ozaki M, Kawashima S, Yamashita T, et al: Overexpression of endothelial nitric oxide synthase accelerates atherosclerotic lesion formation in apoE-deficient mice. J Clin Invest 110: 331-340, 2002.

30. Shi W, Wang X, Shih DM, Laubach VE, Navab M and Lusis AJ: Paradoxical reduction of fatty streak formation in mice lacking endothelial nitric oxide synthase. Circulation 105: 2078-2082, 2002.

31. Closs EI, Scheld JS, Sharafi M and Forstermann U: Substrate supply for nitric-oxide synthase in macrophages and endothelial cells: role of cationic amino acid transporters. Mol Pharmacol 57: 68-74, 2000.

32. Simon A, Plies L, Habermeier A, Martine U, Reining $\mathbf{M}$ and Closs EI: Role of neutral amino acid transport and protein breakdown for substrate supply of nitric oxide synthase in human endothelial cells. Circ Res 93: 813-820, 2003.

33. Erdely A, Kepka-Lenhart D, Salmen-Muniz R, et al: Arginase activities and global arginine bioavailability in wild-type and ApoE-deficient mice: responses to high fat and high cholesterol diets. PLoS One 5: e15253, 2010. 